\title{
A Gender Specific Study of Age and Days of Hospitalization on Indian Health Insurance Claims Data
}

\author{
G SrimanNarayana ${ }^{1}$, Venkata Rajesh Pasupuleti ${ }^{2}$ \\ ${ }^{1}$ Faculty, Institute of Insurance \& Risk Management, Hyderabad, India \\ ${ }^{2}$ Dentist, Texas, USA \\ Email: 1srimannarayana@iirmworld.org.in, 22venkata.dentist@gmail.com
}

\begin{abstract}
There is an increment in medical access by the population in India with health insurance. The relation between the age, days of hospitalization, and claims impacts the insurer's performance. Results have varied across the genders. Claims have positive relationships with age. At the same time, age is found to have a negative association with hospitalization. Cataract and eye-related have formed significant treatments for the aged people and hence had high claim amounts and low hospitalization. Pregnancy and childbirth incurred high treatments for the mid-aged women and therefore had average claims amounts with higher hospitalization days. Young adults were treated for typhoid, communicable diseases, and digestive system issues with higher hospitalization days. Awareness campaigns etc., would help young adults to prevent transferable and digestive system issues. Similarly, the focus of physical exercises and a balanced diet for middle-aged insured would help prevent diseases related to the circulatory system. These proactive steps of insurer might help in lower the claims burden of the insured.
\end{abstract}

Keywords

Claims, Hospitalization, Health insurance, Treatment

\section{Introduction}

India's major population (more than 60\%) is dependent upon the out-of-pocket (OOP) expenditure for medical treatment [19]. This dependency on the OOP concept has resulted in a huge burden upon the lower-income group. It has been the driving factor for the transition of this segment into below the poverty line. There have been multiple insurance schemes undertaken by the government for the low-income group. Besides, community-based health insurance schemes have been actively initiated for the health insurance coverage for both the people in lowincome groups and below the poverty line. These schemes have resulted in supporting the families in the time of the needs.

Failure of the earning member's health has a disastrous effect on the dependent family members as they are hit by both the catastrophic health expenditure and loss of family earnings. Indian people expect the endowment payment at the end of the policy tenure irrespective of the policy type. Health insurance covers only medical claims and has no returns, and hence has lower subscriptions by all society's strata.

A couple of public sector insurers were dominant players in health insurance till 1999. Insurance
Regulatory \& Development Authority of India (IRDAI), as a regulator and insurance development body, has allowed the private sector insurers to offer health insurance to the public in the post-1999 era. This active participation of the private and public sector firms in health insurance has introduced competition and innovation in India's health insurance sector. There are varied features of the health insurance incorporated in the health insurance policies in the present context. It has also provided the insured's flexibility and customization in terms of disease coverage and payment terms. The entry of private players would increase competition among the insurers, which in turn helps in the floating of products with varied features [21].

Out of pocket expenses contribute $62.6 \%$ of India's total health expenditure [16]. A significant segment of the Indian population is still dependent on out of pocket money to cover the catastrophic health expenditure. This has resulted in shifting the low-income group into below the poverty line. Subscription of health insurance would ensure low-income groups to escape from the debt trap [5].

It has been found that there is an increment in the medical access to the BPL and Lower-income group as they are enabled with the health 
insurance schemes provided by the government and the community health insurance. There is increased health insurance penetration in the other income groups due to the increased awareness, higher cost of the medical treatments by the private sector, individual's preference towards access to the latest technological advancements in medical treatments.

Increased access to medical facilities has definitely impacted the quality of the life of the victims. However, there has been an increment of a burden on the insurers. In this context, there is an imminent necessity to study the insured's dependency on the insurers. It is also essential to understand the factors influencing the insured's claims, which in turn impact the profitability of the insurers.

Total or partial amount as insurance coverage for treatment, types of treatments, etc., varies from policy to policy. Hence, the selection of policy depends on the requirements of the individual. A premium of the health insurance policy is dependent on the amount of coverage, morbidity of the proposer, and tenure of coverage. Typical health insurance in the Indian context is subscribed for a tenure of one year.

Insurers generate the premium as part of the revenue. However, it needs to spend the cash for the insured customers' reimbursements for medical treatment. Hence, the insurer needs to predict the cash outflows for smooth business operations. This will help in providing better customer service and also enhances financial budgeting. The budgets help the health insurers decide the proportionate of revenue to be allocated in the long term and short term investments.

Major cash outflows of an insurer are for commissions, administration expenses, and claims incurred. Claims form the lion share of the cash outflows. Claims as expenses are dependent on the inpatient medical visits by the insured. Analysis of the claims would reveal the major treatments the insured undergo and also provide the performance of the insurers.

\section{Literature review}

Research in health needs to focus on genderspecific studies. As the design of the anatomy is gender-specific and treatment has effectiveness according to the gender. Sex and gender are essential variables for medical research, as biased studies results are useful to a specific gender rather than applicable to all [9].

Catastrophic health expenditure for uninsured for the insured population is $26 \%$ and $28 \%$ respectively. Though insured have higher expenditure compared to uninsured. But the amount is still large amount for the out of pocket expenditure [13]. Low socio economic status people are least literate about the insurance coverage and illiteracy amplifies the nonsubscription of insurance coverage. Health insurance usage is least understood by the most vulnerable group [3]. Multiple government insurance schemes and community health insurance schemes have facilitated more number of people to access the health infrastructure [16] with help of insurance coverage.

Men and women age above 40 have a higher incidence of hospitalization compared to other age groups. Women in the age group of 19 to 40 have also been found to have higher hospitalization incidents; these women were found to have utilized hospital services for childbirth [16]. Health expenditure and hospitalization days of women is lesser than the male in the context of India [11], the difference of health expenditure is higher especially in the treatment with OOP.

The number of days of hospitalization is vital information for the insurers. Age has a strong impact on the morbidity rate and leads to more visits for medical treatment. Medical visits for less than a day is generally for the outpatient department (OPD). OPD's are rarely covered by health insurance in the Indian context. At the same time, medical visits for more than a day are called inpatient services. Health insurance generally covers inpatient services.

Inpatient treatment for tenure may lead to hospitalization acquired infections. In surgeries, sepsis is a common infection found in inpatient treatment [13]. These infections result in the long tenure of hospitalization and increased readmission of the patients for further treatment. There is a higher probability for aged patients with comorbidities to be victims of the hospitalization acquired infections.

Readmission leads to a higher number of days of hospitalization. Study finds that the probability of readmission is higher in the children transitioning to adulthood and all aged people suffering from multiple chronic diseases in unplanned admissions [4]. Hospital-acquired infections have also impact 
upon the more extended hospitalization. Sepsis and hospitalization have adverse effects upon the patients with longer treatment of patients [12]. Individuals from lower economic status had higher readmissions in hospitals for treatment. Victims of ICD 10 i.e. issues related to digestive system had highest admissions for the treatment [8].

Type of disease and number of days for treatments are generally dependent upon the age of the patient. So, in general, we can conclude that the number of days of hospitalization is purely dependent on the patient's age and type of the disease \& its treatment. Insurance coverage amount would also influence the number of days of hospitalization, as the higher coverage amount allows the insured to be treated as an inpatient for a longer period.

Older people tend to lose their functional capacity on hospitalization for treatment [18]. This loss of functional capacity would lead to higher treatment costs and higher claim compensation by the insurers. It is found that hospitalization in the geriatric ward results in the prescription of more medicines. Hence the treatment costs increase with age [7]. Expenditure increases with age for both genders; males have a higher frequency of visits to hospitals than females [17].

The number of days of hospitalization before death has increased along with age up to 45 years. However, it remained constant post 45 years, concluding that there is no strong relation with the advanced age with hospitalization days [6]. In addition, there is no relation is found between the age and the hospitalization stay in the age group of 0 to 18 years especially for the kids suffering from congenital heart disease [2].

Treatments of respiratory, chest infections with hospitalization are found to positively impact the quality of life post-treatment. In contrast, hospitalization negatively impacts the quality of life for the treatment of cardiac failure [1]. Hence, the costs involved in the treatment would be higher in cardiac treatments. Influenza has an impact upon all the age groups, primarily upon the age group of 75 years and above. It has an impact on the hospitalization and mortality rates of individuals [10].

Study finds that the Health care alternatives resulted in lower hospitalization rates [15]. The study also found that the decrement of hospitalization is majorly due to decrement in the hospitalization by lower-income groups. Leadership influence, engagement of interprofessional teams, and available resources of hospitals have a strong influence on hospital avoidance programs for chronic disease victims. Lower hospitalization incidents decrease costs for the insurers and a lower burden for the hospitals [14].

This study explores the relation between the number of days of hospitalization, age, and the claimed amount from the claims data.

\section{Data \& Methodology}

Claims data can be used to undertaken for the analysis as they form valuable resources for the health services research [20]. It has to be ensured that the data is not mispresented. Insurance Information Bureau (IIB) collates the data from multiple insurers in Indian context. As a preliminary exercise, 29,347 records are selected from the total data set to undertake the descriptive stats. These records were selected on the basis of disease codes which had the high frequency of claims and higher claim payouts. There were 14 disease code with prominent in both the number and amount of claims. Descriptive stats is undertaken on these 29,347 to understand the pattern of claims w.r.t age and hospitalization days. The data is collected in the period of 2007 to 2010 .

\section{Analysis \& Discussion}

\section{Analysis of the total number of claims and claims amount paid}

29,347 number of claims were paid an amount of Rs. $40,73,39,781.12 .47 .13 \%$ of total claims were raised by males and paid $47.14 \%$ of the total claim amount. Whereas females have raised $46.7 \%$ of the total claims and were paid $45.56 \%$ of the total claim amount. The rest is claimed by others. Table 1 and figure 1 provides the details of the claims settled.

Table 1: Details of the claims settled.

\begin{tabular}{|l|c|c|c|}
\hline & Male & Female & Others \\
\hline $\begin{array}{l}\text { Number of Claims } \\
\text { paid }\end{array}$ & $47.13 \%$ & $46.75 \%$ & $6.12 \%$ \\
\hline $\begin{array}{l}\text { Amount of Claims } \\
\text { paid }\end{array}$ & $47.14 \%$ & $45.56 \%$ & $7.30 \%$ \\
\hline
\end{tabular}




\section{Amount of Claims paid}

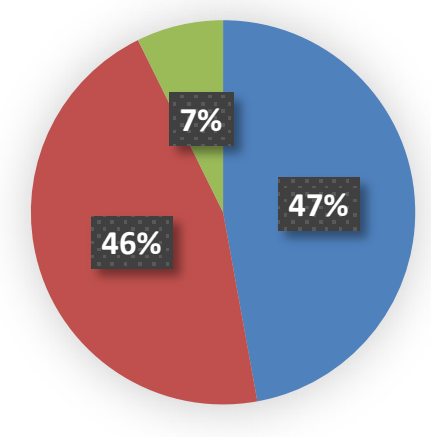

\section{Figure 1: percentage of claims paid with respect to gender.}

\section{Analysis of Number of claims settled.}

It is found that the lion share claims are processed for the treatment of diseases related to the genitourinary system, digestive system \& transmissible diseases. These three types of diseases form $49.1 \%$ of the total number of claims.

On the classification of the data on a gender basis, it is found that the diseases related to the genitourinary system, digestive system, and transmissible diseases form $52.5 \%$ of the total number of male claims. Whereas in females, these diseases form only $47.8 \%$ of total claims by female, and pregnancy-related issues contribute additional claims of $11.4 \%$. Refer table 2 for the number of claims settled.

In the case of other gender, diseases related to the genitourinary system, digestive system, and transmissible diseases form only $33.2 \%$ of the total number of claims by others gender, whereas pregnancy-related claims arise around $14.1 \%$.

Table 2: Details of number of claims settled

\begin{tabular}{|l|c|c|c|c|}
\hline \multirow{2}{*}{ Disease Type } & \multicolumn{3}{c|}{ Number of Claims Settled } \\
\cline { 2 - 4 } & Male & Female & Others & Total \\
\hline Communicable or transmissible diseases & $14.8 \%$ & $12.1 \%$ & $12.8 \%$ & $13.4 \%$ \\
\hline Typhoid and paratyphoid fevers & $4.9 \%$ & $4.0 \%$ & $3.6 \%$ & $4.4 \%$ \\
\hline Infectious gastroenteritis and colitis, unspecified & $4.9 \%$ & $4.9 \%$ & $6.2 \%$ & $5.0 \%$ \\
\hline Diseases of the eye and adnexa & $4.2 \%$ & $4.0 \%$ & $2.9 \%$ & $4.0 \%$ \\
\hline Age-related cataract & $8.3 \%$ & $7.0 \%$ & $6.3 \%$ & $7.6 \%$ \\
\hline Diseases of the circulatory system & $4.7 \%$ & $2.4 \%$ & $4.0 \%$ & $3.6 \%$ \\
\hline Diseases of the respiratory system & $4.3 \%$ & $2.7 \%$ & $4.7 \%$ & $3.6 \%$ \\
\hline Diseases of the digestive system & $11.2 \%$ & $8.7 \%$ & $13.6 \%$ & $10.2 \%$ \\
\hline Diseases of the genitourinary system & $26.5 \%$ & $27.0 \%$ & $6.8 \%$ & $25.5 \%$ \\
\hline Pregnancy, childbirth, and the puerperium & $0.1 \%$ & $11.4 \%$ & $14.1 \%$ & $6.2 \%$ \\
\hline Single delivery by cesarean section & $0.1 \%$ & $5.3 \%$ & $6.8 \%$ & $3.0 \%$ \\
\hline Symptoms, signs, and abnormal clinical and laboratory findings & $4.2 \%$ & $3.3 \%$ & $7.7 \%$ & $4.0 \%$ \\
\hline Fever of other and unknown origin & $6.4 \%$ & $4.9 \%$ & $2.2 \%$ & $5.5 \%$ \\
\hline Injury, poisoning, and certain other consequences of external causes & $5.5 \%$ & $2.3 \%$ & $8.2 \%$ & $4.2 \%$ \\
\hline
\end{tabular}

\section{Analysis of the amount of claims paid}

Diseases related to the digestive system and Communicable or transmissible diseases form $24.3 \%$ of the total amount of claims paid. On gender classification, it is $27.4 \%, 21.6 \%$ \& $21 \%$ for male, female, and others, respectively. Though the genitourinary system's Diseases have the highest number of claims (25.5\%), the amount paid forms only $9.1 \%$ of the total amount paid. Table 3 and figure 2 provide the details of the amounts of claim paid for the different diseases.

Table 3: Details of the amount of claims paid

\begin{tabular}{|c|c|c|c|c|}
\hline \multirow{2}{*}{ Disease Type } & \multicolumn{3}{|c|}{ Amount of Claims Paid } \\
\cline { 2 - 5 } & Male & Female & Others & Total \\
\hline Communicable or transmissible diseases & $12.0 \%$ & $9.4 \%$ & $8.0 \%$ & $10.5 \%$ \\
\hline
\end{tabular}




\begin{tabular}{|c|c|c|c|c|}
\hline Typhoid and paratyphoid fevers & $4.0 \%$ & $3.1 \%$ & $2.6 \%$ & $3.5 \%$ \\
\hline Infectious gastroenteritis and colitis, unspecified & $3.2 \%$ & $3.1 \%$ & $2.9 \%$ & $3.1 \%$ \\
\hline Diseases of the eye and adnexa & $5.9 \%$ & $5.5 \%$ & $3.5 \%$ & $5.5 \%$ \\
\hline Age-related cataract & $13.6 \%$ & $11.8 \%$ & $7.1 \%$ & $12.3 \%$ \\
\hline Diseases of the circulatory system & $17.9 \%$ & $7.6 \%$ & $10.7 \%$ & $12.7 \%$ \\
\hline Diseases of the respiratory system & $5.0 \%$ & $3.1 \%$ & $3.3 \%$ & $4.0 \%$ \\
\hline Diseases of the digestive system & $15.4 \%$ & $12.2 \%$ & $13.0 \%$ & $13.8 \%$ \\
\hline Diseases of the genitourinary system & $9.3 \%$ & $9.1 \%$ & $7.8 \%$ & $9.1 \%$ \\
\hline Pregnancy, childbirth, and the puerperium & $0.2 \%$ & $16.1 \%$ & $15.4 \%$ & $8.5 \%$ \\
\hline Single delivery by cesarean section & $0.2 \%$ & $10.7 \%$ & $12.1 \%$ & $5.9 \%$ \\
\hline Symptoms, signs, and abnormal clinical and laboratory findings & $3.6 \%$ & $2.9 \%$ & $4.8 \%$ & $3.4 \%$ \\
\hline Fever of other and unknown origin & $4.6 \%$ & $3.7 \%$ & $1.0 \%$ & $3.9 \%$ \\
\hline Injury, poisoning, and certain other consequences of external causes & $5.3 \%$ & $1.6 \%$ & $7.8 \%$ & $3.8 \%$ \\
\hline
\end{tabular}

Age-related cataract and Diseases of the circulatory system put together form only $11.2 \%$ of the total number of claims, but the amounts form around $25 \%$ of the total claim amount paid. That is $31.5 \%$ of claims amount processed for cataract treatment $(13.6 \%)$ and circulatory system diseases $(17.9 \%)$ for males. For women, $19.4 \%$ of the total claims amount is paid to treat cataract
(11.8\%) and circulatory system diseases (7.6\%). In other gender, $17.8 \%$ is paid for the circulatory system diseases $(10.7 \%)$ and cataract treatment $(7.1 \%)$. Both the male and other gender have higher treatment claims for circulatory system diseases. Claims amount paid for pregnancy related and cesarean operations forms $26.8 \%$ for female and $27.5 \%$ for others gender.

\section{Amout of Claims Paid}

Injury, poisoning and certain other consequences of external causes

Fever of other and unknown origin

Symptoms, signs and abnormal clinical and laboratory findings

Single delivery by caesarean section

Pregnancy, childbirth and the puerperium

Diseases of the genitourinary system

Diseases of the digestive system

Diseases of the respiratory system

Diseases of the circulatory system

Age-related cataract

Diseases of the eye and adnexa

Infectious gastroenteritis and colitis, unspecified

Typhoid and paratyphoid fevers

Communicable or transmissible diseases

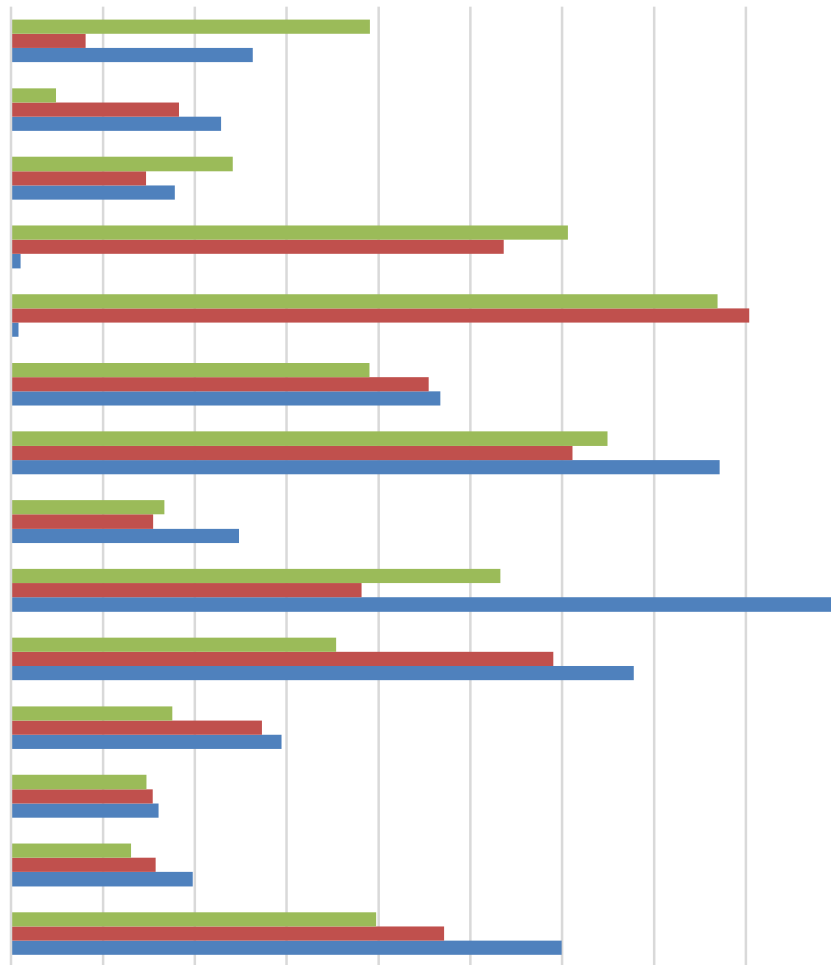

$\begin{array}{lllllllllll}0.0 \% & 2.0 \% & 4.0 \% & 6.0 \% & 8.0 \% & 10.0 \% & 12.0 \% & 14.0 \% & 16.0 \% & 18.0 \% & 20.0 \%\end{array}$

Others $\square$ Female $\square$ Male

Figure 2: Details of the amount of claims paid 


\section{Analysis of Duration of Hospitalization}

It is found that the on average male spends 19 days in hospitalization for treatments, whereas females spend 21 days. In the case of other gender, they spend an average of 32 days for the treatments. Refer table 4 for the details of the hospitalization for treatment of the diseases.

Claims paid for typhoid treatment is hardly $3.5 \%$ of total claim amount, but has the highest hospitalization days across the genders (in the range of 39-44 days). Similarly, the treatment of diseases related to the genitourinary system had a higher number of claims (25\%) needs a low number of hospitalization days. One of the highest claims amounts is paid for cataract treatment has the least number of hospitalization days. Pregnancy and cesarean operations have higher claims paid and also had higher hospitalization days.

Most of the disease treatment has a requirement of hospitalization for 30 to 40 days. However, other gender is found to have higher hospitalization in comparison to male $\&$ female.

\section{Table 4: Details of hospitalization days for the treatment of diseases}

\begin{tabular}{|l|c|c|c|c|}
\hline \multicolumn{1}{|c|}{ Disease Type } & Male & Female & Others & Total \\
\hline Communicable or transmissible diseases & 26 & 24 & 31 & 26 \\
\hline Typhoid and paratyphoid fevers & 42 & 44 & 39 & 42 \\
\hline Infectious gastroenteritis and colitis, unspecified & 23 & 23 & 30 & 23 \\
\hline Diseases of the eye and adnexa & 7 & 8 & 11 & 8 \\
\hline Age-related cataract & 5 & 5 & 6 & 5 \\
\hline Diseases of the circulatory system & 30 & 34 & 38 & 32 \\
\hline Diseases of the respiratory system & 28 & 32 & 32 & 30 \\
\hline Diseases of the digestive system & 21 & 25 & 24 & 23 \\
\hline Diseases of the genitourinary system & 7 & 8 & 32 & 8 \\
\hline Pregnancy, childbirth, and the puerperium & 36 & 29 & 43 & 31 \\
\hline Single delivery by cesarean section & 21 & 32 & 47 & 34 \\
\hline Symptoms, signs, and abnormal clinical and laboratory findings & 26 & 27 & 39 & 28 \\
\hline Fever of other and unknown origin & 32 & 33 & 44 & 33 \\
\hline Injury, poisoning, and certain other consequences of external causes & 30 & 32 & 32 & 30 \\
\hline Grand Total & 19 & 21 & 32 & 21 \\
\hline
\end{tabular}

\section{Analysis of the age of Insured}

Old adults with an average age of more than 50 were majorly treated for the cataract, diseases related to eye, and circulatory system. Refer table 5 for the average age of the patients for the respective disease treatment. These treatments also have higher claims paid. At the same time, middle-aged adults were treated for diseases related to the genitourinary system, the digestive system, and injuries. These middle-aged adult treatments had lower claims paid. Young adults were treated for communicable diseases, pregnancy, cesarean, which were higher claims, and typhoid, which had lower claims but higher hospitalization days.

Table 5: Details of the age of the genders

\begin{tabular}{|l|c|c|c|}
\hline \multicolumn{1}{|c|}{ Disease Type } & Male & Female & Others \\
\hline Communicable or transmissible diseases & 27 & 28 & 28 \\
\hline Typhoid and paratyphoid fevers & 22 & 23 & 30 \\
\hline Infectious gastroenteritis and colitis, unspecified & 23 & 26 & 30 \\
\hline Diseases of the eye and adnexa & 59 & 58 & 52 \\
\hline Age-related cataract & 60 & 59 & 57 \\
\hline Diseases of the circulatory system & 52 & 53 & 46 \\
\hline Diseases of the respiratory system & 29 & 29 & 23 \\
\hline
\end{tabular}




\begin{tabular}{|l|l|l|l|}
\hline Diseases of the digestive system & 34 & 35 & 35 \\
\hline Diseases of the genitourinary system & 42 & 38 & 34 \\
\hline Pregnancy, childbirth, and the puerperium & 35 & 27 & 27 \\
\hline Single delivery by cesarean section & 28 & 28 & 27 \\
\hline Symptoms, signs, and abnormal clinical and laboratory findings & 29 & 30 & 30 \\
\hline Fever of other and unknown origin & 28 & 31 & 27 \\
\hline Injury, poisoning, and certain other consequences of external causes & 33 & 37 & 32 \\
\hline
\end{tabular}

\section{Analysis of Age, claims paid, and hospitalization days}

\section{Correlation Analysis for all genders}

It is found that the age and hospitalization days has a significant negative relation of -0.71 . (refer table 6) Most of the claims were due to the Diseases related to the genitourinary system, which has one of the least number of hospitalization days; however, it is predominant in young adults. Diseases like Age-related cataract were treated in 5 to 8 days, and hence old age people were hospitalized for a lesser number of days. The negative value signifies that the costs are high for these treatments rather than the hospitalization days. Age and claims paid have a significant positive relation of 0.46 . This relation substantiates that treatment costs have increased as lower hospitalization days have been found for the old age people. Claims paid has a positive relation with hospitalization days as the increment in hospitalization days does increase the costs of the treatment. However, the relation is not significant enough.

Table 6: Correlation matrix of hospitalization days, claims and age for all gender

\begin{tabular}{|l|c|c|c|}
\hline & $\begin{array}{c}\text { Hospitalization } \\
\text { days }\end{array}$ & $\begin{array}{c}\text { Claims } \\
\text { paid }\end{array}$ & Age \\
\hline $\begin{array}{l}\text { Hospitalization } \\
\text { days }\end{array}$ & 1 & & \\
\hline Claims paid & 0.16 & 1 & \\
\hline Age & -0.71 & 0.46 & 1 \\
\hline
\end{tabular}

Correlation analysis for Male

Age has a negative relation of -0.67 with hospitalization days and positive relation of 0.47 with the claims paid (refer table 7). In male, aged people were mostly treated for cataract, eye problems, circulatory system diseases, which also had significant claims paid, but eye treatments had the least hospitalization days. Whereas, Communicable or transmissible diseases, diseases related to the digestive system, etc., were treated for young adults with higher hospitalization days. Diseases related to the digestive system and circulatory system had higher claims paid and also had higher hospitalization day and hence have a positive relation of 0.10 .

Table 7: Correlation matrix of hospitalization days, claims and age for male gender

\begin{tabular}{|l|c|c|c|}
\hline & $\begin{array}{c}\text { Hospitalization } \\
\text { days }\end{array}$ & $\begin{array}{c}\text { Claims } \\
\text { paid }\end{array}$ & Age \\
\hline $\begin{array}{l}\text { Hospitalization } \\
\text { days }\end{array}$ & 1 & & \\
\hline Claims paid & 0.10 & 1 & \\
\hline Age & -0.67 & 0.47 & 1 \\
\hline
\end{tabular}

Correlation analysis for Female

Old age females were treated for age-related cataract, eye-related issues, and had fewer hospitalization days. Young women had major treatments for pregnancy, cesarean operation, etc., which need longer hospitalization days. Hence, age has a negative relation of -0.62 with the hospitalization days (refer table 8). Higher claims were processed for the treatment of cataract, eyerelated diseases, and cesarean operations. This has also resulted in a positive relation of 0.48 between the age and claims paid. Other than eye treatments, the rest of the treatments needed a higher number of hospitalization days for the female and hence has a positive relationship between the claims paid and hospitalization days of 0.20 .

Table 8: Correlation matrix of hospitalization days, claims and age for female gender

\begin{tabular}{|l|c|c|c|}
\hline & $\begin{array}{c}\text { Hospitalizatio } \\
\text { n days }\end{array}$ & $\begin{array}{c}\text { Claims } \\
\text { paid }\end{array}$ & Age \\
\hline $\begin{array}{l}\text { Hospitalizatio } \\
\text { n days }\end{array}$ & 1 & & \\
\hline Claims paid & 0.20 & 1 & \\
\hline Age & -0.62 & 0.48 & 1 \\
\hline
\end{tabular}




\section{Correlation analysis for others}

Old aged other gender were explicitly treated for cataract and eye-related issues and, hence, the negative relation of -0.77 between the age and hospitalization days (refer table 9). Middle-aged adults were treated for the diseases of the circulatory system. Hence, there is a positive relationship between the claims paid, and the age as the cataract and circulatory system diseases involve high costs. Whereas the rest of the diseases were treated for young adults who had higher hospitalization days. Hence there is a little positive relation of 0.07 between the claims paid and hospitalization days.

Table 9: Correlation matrix of hospitalization days, claims and age for other gender

\begin{tabular}{|l|c|c|c|}
\hline & $\begin{array}{c}\text { Hospitalization } \\
\text { days }\end{array}$ & $\begin{array}{c}\text { Claims } \\
\text { paid }\end{array}$ & Age \\
\hline $\begin{array}{l}\text { Hospitalization } \\
\text { days }\end{array}$ & 1 & & \\
\hline Claims paid & 0.071074 & 1 & \\
\hline Age & -0.77115 & 0.390465 & 1 \\
\hline
\end{tabular}

Summary

The highest number of claims are being claimed for the treatment related to diseases of the genitourinary. This treatment has an average hospitalization of 7 to 8 days for both the male and female. This is being treated for the middle age (around 40) adults. Claims for these diseases' treatment are hardly $9 \%$ of total claims processed and are similar across the genders.

Pregnancy and delivery has a total number claims of $9 \%, 14.4 \%$ of claims amount is processed for the same. This is majorly due to the higher number of hospitalization days (more than a month). These claims can be reduced by better nutrition and care at the pre-delivery stage.

Others gender has a higher number of days of hospitalization for pregnancy, delivery issues, and genitourinary diseases, resulting in higher claims amount to be paid.

Age-related cataract and eye-related issues are treated in a low number of hospitalization. However, due to the higher costs included for the technology, the higher claims amounts are processed for the treatment. Insurers need to negotiate and standardize the treatment costs with the network hospitals to achieve lower claims.

Advance aged adults (50+) suffer from diseases of the circulatory system, which needs higher hospitalization days for treatment and has higher claims amount processed. Individuals need to be motivated to undertake exercises and nutrition from middle age to fit. Insurers can provide an additional monetary discount to individuals with a habit of physical exercise; this shall motivate them to undertake additional care for the circulatory system.

Young adults are suffering from communicable and transmissible diseases and digestive system. More than $23 \%$ of total claims are being processed for the treatment of these diseases. Treatment of these diseases needs a hospitalization of more than a month. Young adults need to be motivated to undertake selfhygiene [14, 15]. Sanitized environments help in the prevention of transmissible diseases. Young adults also need to undertake special care for food habits.

Other than age-related cataract treatment, the rest of the diseases had claim amount for the older adults. Hence, a negative relationship is found between age and claims paid. At the same time, claims paid have a positive relation with hospitalization days and age. As the age increases, claims paid to the insured is going to be higher.

\section{References}

[1] Albuquerque, D. A. F., Al, M. J., Severens, J. L., Al, M. J., Severens, J. L., Koymans, R., Riistama, J., ... Pauws, S. (August 03, 2020). Impact of hospitalisation on health-related quality of life in patients with chronic heart failure. Health and Quality of Life Outcomes. 2020;18, 1.

[2] Al-Radi, O.O. Are neonatal age and small weight predictive of in-hospital death and prolonged hospital stay in children undergoing heart surgery? The Cardiothoracic Surgeon. 2020; 28, 1. https://doi.org/10.1186/s43057-019-0013-9

[3] Barnes, A.J., Hanoch, Y. Knowledge and understanding of health insurance: challenges and remedies. Israel Journal of Health Policy Research. 2017.6 6, 40. https://doi.org/10.1186/s13584-017-0163-2

[4] Berry, J. G., Gay, J. C., Joynt, M. K., Coleman, E. A., Bucholz, E. M., O’Neill, M. R., Blaine, K., ... Hall, M. (February 27, 2018). Age trends in 30 day hospital readmissions: US national retrospective analysis. BMJ.2018; 
[5] Devadasan, N., Criel, B., Van, D. W., Ranson, K., Van, D. S. P. Indian community health insurance schemes provide partial protection against catastrophic health expenditure. BMC health services research.2007;

[6] Dixon, Tracy, Shaw, Mary, Frankel, Stephen, \& Ebrahim, Shah. (n.d.). Hospital admissions, age, and death: retrospective cohort study. BMJ Publishing Group Ltd. 2004;

[7] Johansen, J.S., Halvorsen, K.H., Svendsen, K. et al. The impact of hospitalisation to geriatric wards on the use of medications and potentially inappropriate medications - a health register study. BMC Geriatric.2020; 20, 190 . https://doi.org/10.1186/s12877-02001585-w

[8] Johnson, L., Cornish, R., Boyd, A. et al. Socio-demographic patterns in hospital admissions and accident and emergency attendances among young people using linkage to NHS Hospital Episode Statistics: results from the Avon Longitudinal Study of Parents and Children. BMC Health Service Research. 2019; 19, 134 https://doi.org/10.1186/s12913-019-3922-7

[9] Mason, R.. Doing better: eleven ways to improve the integration of sex and gender in health research proposals. Research Integrity and Peer Review.2020; 5, 1.

[10] Matias, G., Taylor, R. J., Haguinet, F., Schuck-Paim, C., Lustig, R. L., Fleming, D. M., \& SpringerLink (2016). Modelling estimates of age-specific influenza-related hospitalisation and mortality in the United Kingdom. BMC public health. 2016; 16,1-9

[11] Moradhvaj, Nandita Saikia, Gender disparities in health care expenditures and financing strategies (HCFS) for inpatient care in India, SSM - Population Health.2019; 9

[12] Öhrn, Annica, Elfström, Johan, Tropp, Hans, \& Rutberg, Hans. What can we learn from patient claims? - A retrospective analysis of incidence and patterns of adverse events after orthopaedic procedures in Sweden. Patient Safety in Surgery .2012; 6;

[13] PrinjaS, Bahuguna P, GuptaI,Chowdhury S, TrivediM Role of insurance in determining utilization of healthcare and financial risk protection in India. PLOSONE. 2019; 14(2):e0211793.https://doi.org/10.1371/journ al.pone. 021179 .
[14] Sarkies, M., Long, J. C., Pomare, C., Wu, W., Clay-Williams, R., Nguyen, H. M., FrancisAuton, E., ... Braithwaite, J. Avoiding unnecessary hospitalisation for patients with chronic conditions: a systematic review of implementation determinants for hospital avoidance programmes. Implementation Science.2020; 15, 1.

[15] Schifano, Patrizia, Marinacci, Chiara, Cesaroni, Giulia, Belleudi, Valeria, Caranci, Nicola, Russo, Antonio, \& Perucci, Carlo A. Temporal and geographic heterogeneity of the association between socioeconomic position and hospitalisation in Italy: an income based indicator. BioMed Central Ltd. 2009

[16] Shyamkumar Sriram, \& M. Mahmud Khan.. Effect of health insurance program for the poor on out-of-pocket inpatient care cost in India: evidence from a nationally representative cross-sectional survey. $B M C$ Health Services Research. 2020; 20, 1, 1-21.

[17] Tamiya, N., Kashiwagi, M., Takahashi, Hideto Takahashi \& Haruko Noguchi. Descriptive analysis of service use covered by long-term care insurance in Japan - based on population-based claims data. BMC Health Service Research .2014; 14, P125. https://doi.org/10.1186/1472-6963-14-S2P125

[18] Tanja Ahlin, Mark Nichter \& Gopukrishnan Pillai. Health insurance in India: what do we know and why is ethnographic research needed, Anthropology \& Medicine, 2016, 23:1, 102-124, DOI: 10.1080/13648470.2015.1135787

[19] Tatiane, C. C., Adriana, P. V., Alessandro, F. J., Vânia, F. S. M., \& Paulo, J. F. V. B. Impact of hospitalization on the functional capacity of the elderly: A cohort study. Revista Brasileira De Geriatria E Gerontologia.2018; 21, 2, 134-142.

[20] Tyree PT, Lind BK, Lafferty WE. Challenges of using medical insurance claims data for utilization analysis. American Journal of Medical Quality. 2006; 21(4):269-275. doi:10.1177/1062860606288774

[21] World Health Organization. Health systems: Improving performance. Geneva: World Health Organization. 2000; 